\title{
EL SANGRADOR Y LA BIGOTERA: FUENTES Y SENTIDO DE UN CHISTE DE COQUÍN EN EL MÉDICO DE SU HONRA
}

\author{
Antonio Sánchez Jiménez \\ Professeur Ordinaire de Littérature Espagnole \\ Université de Neuchâtel \\ Institut de Langues et Littératures Hispaniques \\ Espace Louis-Agassiz 1 \\ CH-2000 Neuchâtel. Suiza \\ antonio.sanchez@unine.ch
}

[Anuario calderoniano (ISSN: 1888-8046), 7, 2014, pp. 229-254]

Dentro del corpus calderoniano, e incluso áureo, El médico de su honra (c. 1635) ${ }^{1}$ es una de las obras más analizadas y estudiadas por la

${ }^{1}$ El médico de su honra se publicó en la Segunda parte de comedias de Calderón en 1637, pero se supone escrita unos años antes. Don W. Cruickshank, 2010, p. 13, la data entre 1633 y 1635, mientras que Daniel Rogers, 1985, sugiere que se pudo escribir antes de noviembre de 1633. Sin embargo, la fecha más aceptada es 1635, como sostiene Ana Armendáriz, 2007, p. 15, basándose en la noticia de una representación de la comedia en palacio en ese año (Shergold y Varey, 1961, p. 281). Tenemos testimonios de una representación anterior de una obra de ese título en 1628 o 1629, pero corresponde a la atribuida a Lope de Vega (Shergold y Varey, 1961, p. 281). 
crítica $^{2}$, cuya atención testifica lo impactante del trágico «sangrador» don Gutierre Alfonso Solís, la inocente doña Mencía y el rey don Pedro $^{3}$. Sin embargo, los trabajos sobre esta tragedia no han logrado un consenso sobre el sentido de la obra, y sí más bien una hidra de lecturas que demuestra la diversidad de los estudios áureos y el potencial de la comedia. Si en algo concuerdan los críticos es en la complejidad del drama, que para algunos llega al extremo de ser deliberadamente ambiguo ${ }^{4}$. Esta pluralidad de sentidos, o por lo menos de lecturas, afecta también a uno de los personajes secundarios de la tragedia, el gracioso Coquín. Sus burlas y veras han suscitado un notable revuelo y una serie de estudios ad hoc de calderonistas como Ignacio Arellano, Anne J. Cruz, Ángel M. García Gómez o Marc Vitse 5 .

Nuestro trabajo aprovecha su estela para esclarecer la función de Coquín analizando uno de sus más famosos chistes, el del capón con bigotera, que examinaremos en relación con sus probables fuentes en las Rimas de Tomé de Burguillos, de Lope de Vega. Concretamente, utilizamos ese y otros testimonios sobre las bigoteras para aclarar el paso de hombre de burlas a nuncio de veras que experimenta Coquín, transición que matizaremos mostrando la graciosidad del criado en las dos primeras jornadas. Esta elucidación devuelve a Coquín a la graciosidad que se ejemplifica en el chiste sobre el capón con bigotera, pero también en otros intercambios jocosos de la tragedia, como el pacto sobre los dientes. Así, el contexto de literatura satírica sobre la bigotera nos servirá para mostrar cómo Calderón adaptó material previo para hacerlo funcionar en su tragedia.

${ }^{2}$ Christophe Couderc, 2010, p. 67, la considera la obra calderoniana «que ha generado mayor bibliografia crítica».

${ }^{3}$ La crítica ha señalado la importancia de la estética de la admiratio y el movere en la obra: Arellano, 1995, p. 126; Couderc, 2010, p. 96; Rogers, 1965, p. 273. Concretamente, Couderc, 2010, utiliza la división del Pinciano entre tragedia patética (de fin estético) y morata (de fin moral).

${ }^{4}$ Armendáriz, 2007, p. 12; Blue, 1999, p. 415; Casa, 1997, p. 140; Pérez Magallón, 2012, pp. 12-13. El extremo relativista de esta opinión es el «pluralismo» que propone Stroud, 1990. Más prudente es la postura de Armendáriz, 2007, p. 17, que relaciona la supuesta ambigüedad con la «capacidad de conflicto» del resorte dramático del tema del honor, idea propuesta en general por Arellano, 1995, p. 126, para quien el tema del honor es ante todo una fuente de tensión dramática. José María Ruano de la Haza, 1988, p. 52, expresó una opinión semejante.

5 Arellano, 1992; Cruz, 2001; García Gómez, 1983; Vitse, 1983. 
Antes de llevar a cabo esta contextualización conviene examinar lo que ha propuesto la crítica sobre Coquín y su transición. Para revisar el estado de la cuestión conviene recordar que el papel de Coquín en la obra es en parte convencional y típico de la figura del gracioso, y en parte es especial e inesperado. Coquín se presenta en la tragedia como criado y mozo de cuadra de don Gutierre, manifestando de entrada un gusto por la salida de tono y la anfibología típico de los graciosos (vv. 460-465). De hecho, el infante don Enrique le reconoce inmediatamente como hombre de humor ${ }^{6}$, disculpándole ante la preocupación de don Gutierre, que - para regocijo del público- se avergüenza de los indecorosos comentarios del criado:

Don Gutierre Aparta, necio.

DOn EnRIQUe

¿Por qué?

Dejalde, su humor le abona.

(vv. 454-455)

Ese humor caracterizará la autodefinición de Coquín en la siguiente escena que protagoniza: su presentación ante el rey. En ella Coquín le explica al monarca cuál es su "oficio", que incluye elementos de mensajero y criado (vv. 751-754). Pero también, y sobre todo, Coquín se define como bufón, hombre de placer:

Soy cofrade del contento,
el pesar no sé quién es
ni aun para servirle; en fin,
soy, aquí donde me veis,
mayordomo de la risa,
gentilhombre del placer
y camarero del gusto,
pues que me visto con él.

(vv. 755-761)

${ }^{6}$ Armendáriz, 2007, p. 202, señala que el nombre del personaje («Coquín») tiene connotaciones picarescas. Pese a la peregrina sugerencia de Gaylord Randel, 1983, p. 878, que ve la palabra como diminutivo de "coco» (la fruta), el nombre proviene del francés (coquin: pícaro) a través de la germanía. Calderón utilizó el sufijo en otras ocasiones para crear nombres de graciosos. 
Don Pedro resume la intervención del gracioso preguntando si Coquín es, en fin, «hombre que a cargo tenéis / la risa» (vv. 769-771), lo que este confirma y ejemplifica cubriéndose ante el monarca, acción que era prerrogativa de grandes de España y —es su caso- de bufones:

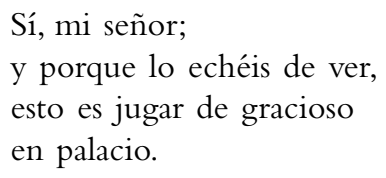

El «está muy bien» que añade el monarca (v. 774) y las siguientes intervenciones de Coquín confirman el papel, con chistes como su respuesta a doña Mencía, sus consejos a don Gutierre, o las bromas sobre los estudiantes, el capón con bigotera y el animal risible (vv. 1221-34, 1253-1326 y 1441-1524). Además de esta graciosidad, el personaje muestra otras características típicas de la figura del donaire, como la cobardía y el sentido práctico y poco caballeresco del honor ${ }^{7}$, que se oponen al arrojo y pundonor de su amo (vv. 1253-1307). A esto Coquín añade un materialismo que evidencia en una respuesta que lleva implícita una petición de mercedes, como reconoce el monarca:

\begin{tabular}{ll} 
Rey & \multicolumn{1}{c}{ ¿Cómo va? } \\
Coquín & Responderé a lo estudiante. \\
REY & ¿Cómo? \\
Coquín & «De corpore bene, \\
ReY & $\begin{array}{l}\text { pero de pecunis male». } \\
\text { Cocid algo, pues sabéis, }\end{array}$ \\
& tenéis aquí cien escudos.
\end{tabular}

(vv. 1449-1455)

Hasta aquí, el papel de Coquín resulta típico de la figura del donaire tal y como la entendieron los dramaturgos áureos.

${ }^{7}$ Armendáriz, 2007, pp. 202-203; Bryans, 1982, pp. 597-598. 
Sin embargo, dos detalles complican tal conclusión: la seria reacción de don Gutierre y don Pedro ante los chascarrillos de Coquín y, sobre todo, la transformación de este de hombre de burlas en nuncio de veras. En cuanto a la primera, la crítica ha notado que los dos protagonistas de la tragedia no celebran los chistes de Coquín, e incluso que le incitan a la seriedad. Así, en la segunda jornada el rey clasifica el epigrama del capón de "frialdad» (v. 1485), en una escena que analizaremos abajo. A continuación, y ya en la tercera jornada, don Pedro recibe una alusión al pacto o "concierto» de la primera jornada (el gracioso se había comprometido a hacer reír al monarca y ser recompensado, o a ser castigado con perder los dientes si no tenía éxito con sus bromas [vv. 775-808]) con un «no es ahora tiempo de risa» (v. 2769). Del mismo modo, también don Gutierre rechaza un chascarrillo de Coquín con un "aparta, necio» (v. 454), y luego repudia una jocosa sugerencia del criado con un indignado " $i$ Vive Dios, necio villano / que te mate por mi mano!» (vv. 1264-1265). Además, Coquín parece adoptar esta seriedad en la tercera jornada, en la que se define de modo muy diferente a las anteriores:

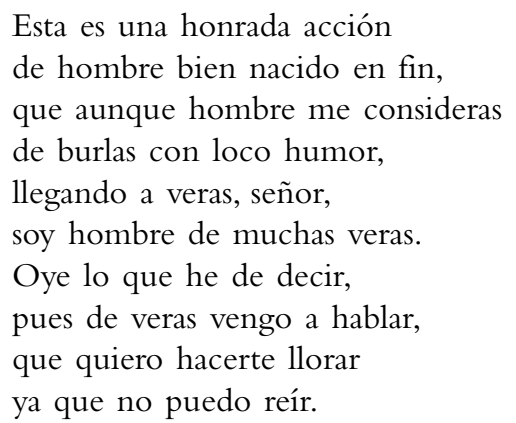

(vv. 2728-2737)

Este paso de las burlas a las veras se aprecia también en el rol del personaje, y no solo en sus autodefiniciones. En la tercera jornada Coquín se dedica más a transmitir malas noticias (vv. 2723-2764), como el nuncio de una tragedia, que a hacer juegos de palabras ${ }^{8}$. La única traza de su papel anterior es un chiste sobre la hipocondría (vv.

8 García Gómez, 1983, p. 1027. 
2418-2428) y, sobre todo, la mención al pacto de la dentadura (vv. 2736-2737 y 2766-2770). La disminución de sus graciosidades se percibe a nivel estadístico al comparar el número de versos que Coquín enuncia en las diversas jornadas, que pasa de 115 en la primera a 106.5 en la segunda y, finalmente, a 79 en la tercera. Es una evolución natural: a menos gracias, menos gracioso, desarrollo que va en relación inversa con el avance de la trama trágica. Como resaltara Vitse ${ }^{9}$, este paso a las veras y esta pérdida de peso escénico conlleva un cambio un tanto siniestro: en la tercera jornada Coquín rompe con el rol del gracioso lopesco, siempre fiel criado, y denuncia a su señor ${ }^{10}$.

La crítica ha notado la peculiar caracterización de Coquín y ha enfatizado su incapacidad cómica. Así, algunos resaltan lo aburrido de sus bromas ${ }^{11}$, o su «disolución» y «anulación como figura del donaire» «en el ambiente trágico» de la obra ${ }^{12}$. Armendáriz incluso subraya que «sus chistes no funcionan en ningún momento de la comedia. Coquín no es gracioso. Las circunstancias trágicas acabarán por excluirle, [. . .] lo que refuerza el universo trágico que constituye la obra» ${ }^{13}$. La opinión de García Gómez resume tal tendencia crítica al subrayar la «dudosa graciosidad» de Coquín, "gracioso en quien el humor no parece cuajar», con "chistes cuya graciosidad es en todo caso dudosa»: "Coquín es, pues, un personaje cuyas características convencionales han quedado fuertemente desdibujadas. Como "gracioso" su humor no hace mella ni en el rey ni en Gutierre ni incluso en Mencía (II, 208) y, posiblemente, tampoco en el público» ${ }^{14}$. Esa opinión ha llevado a algunos a buscar connotaciones ominosas para casi todas las bromas de Coquín, incluyendo su referencia satírica a la hipocondría ${ }^{15}$. Algo más divergen juicios como el de Jonathan T. Cull ${ }^{16}$, que sugiere que los chistes de Coquín esconden referencias - muy serias- a la impotencia de Gutierre, o de Anne J. Cruz, que considera que el cuento

${ }^{9}$ Vitse, 1983, pp. 1067 y 1071-72.

${ }^{10}$ Vitse, 1983, p. 1067.

11 Jones, 1961, p. XX.

12 Escudero, 2010, p. 117.

13 Armendáriz, 2007, p. 203. La propia autora, 2007, p. 214, caracteriza las intervenciones de Coquín como «chistes sin gracia».

14 García Gómez, 1983, pp. 1025, 1026, 1030 y 1035.

15 Bryans, 1982, p. 598.

16 Cull, 1982, pp. 129-130. 
del capón simboliza la incapacidad — metafórica y tal vez sexual- de Gutierre y el rey ${ }^{17}$. Estos estudiosos llevan a un extremo la tendencia a minimizar la faceta cómica de Coquín. Por tanto, se deben incluir en la línea que ve al personaje como fuente de premoniciones trági$\mathrm{cas}^{18}$, e incluso como portavoz de la muy seria opinión del dramaturgo $^{19}$.

Estas interpretaciones se suelen caracterizar por cierta intensidad emocional, pues los estudiosos se alinean bien al lado de Coquín, bien contra él. El posicionamiento refleja una interpretación determinada de la tragedia, y en concreto de los personajes centrales de don Gutierre y don Pedro, a quienes Coquín sirve ya para denigrar, ya para defender. Así, si los críticos consideran que don Gutierre es un asesino repugnante o, por lo menos, sometido a una ideología antipática para el dramaturgo — según sugiere la "escuela inglesa» liderada por Alexander A. Parker ${ }^{20}$ - aplauden que Coquín le abandone y delate ${ }^{21}$; por el contrario, si entienden al noble como un héroe trágico acosado por exigencias imposibles ${ }^{22}$, censuran o matizan las acciones de su criado. De modo semejante, si leen al rey don Pedro en su faceta cruel, consideran prueba de ella el pacto sobre los dientes, así como su incapacidad para la risa ${ }^{23}$. De manera opuesta, los pocos estudiosos que

17 Cruz, 2001, pp. 229-230.

${ }^{18}$ Aczue Castillón, 2002, p. 67; Blue, 1979-1980; Bryans, 1982, p. 597; Fox, 1982, p. 33.

19 Cull, 1982, p. 129; Díez Borque, 1978, p. 53; Hesse, 1976, p. 13; Sullivan, 1981, p. 360; Parker, 1991, pp. 284-285; Sloman, 1958, p. 45; Wiltrout, 1983, p. 662. Felipe B. Pedraza Jiménez, 2000, pp. 71-72, comenta y refuta esta tendencia a pintar a Calderón como un hombre sin humor.

${ }^{20}$ Parker, 1976, p. 332; Parker, 1991; Couderc, 2010, p. 68; Vitse, 2002, pp. 326327. Armendáriz, 2007, p. 106, resume esta corriente. También censura este punto de vista Vitse, 2001, p. 13, que lo había expuesto en un magistral artículo, 1983, p. 1065. Para un panorama general de la recepción del personaje de don Gutierre, incluyendo la reacción inglesa, sus seguidores y detractores, véase Armendáriz, 2002.

21 Cruickshank, 2010, p. 54, llega a calificar al gracioso de «altruísta, quizá hasta noble y valiente».

${ }^{22}$ La postura más coherente en este sentido es la de Vitse, 2002, p. 163. De hecho, son varios los trabajos del erudito francés en defensa de don Gutierre, «el peor comprendido de todos los protagonistas trágicos de Calderón» (Vitse, 1997, p. 63). Véase también Couderc, 2010, p. 72.

23 Armendáriz, 2007, p. 204; Bryans, 1982, p. 602; García Gómez, 1983, p. 1025; Jones, 1961, p. XX; King, 1971, p. 46. Nótese al respecto la antipatía que muestra 
ven al rey de El médico de su honra en su faceta de don Pedro I «el Justiciero» celebran su seriedad ante los chistes de Coquín como muestra de autocontrol ${ }^{24}$. Es decir, la visión de Coquín que ostentan los estudiosos se halla unida a la que ya tuvieran de los dos personajes principales y al sentido que otorgaran a la tragedia.

Resulta legítimo utilizar al gracioso como piedra de toque de los demás personajes, e incluso leer en sus chistes comentarios sobre la obra en general, pues encontramos en Calderón ejemplos que lo justifican ${ }^{25}$. Sin embargo, para entender a Coquín conviene separarse por un momento de esta práctica para examinar las intervenciones del personaje en su contexto de graciosidad, estrategia que nos lleva a detenernos en el desafio de la dentadura, en el que se integra nuestro chiste del capón con bigotera. Como ya hemos señalado, cuando Coquín llega a palacio buscando a su amo se encuentra al rey, ante el que se turba, temiendo un severo castigo (vv. 708-710). Entonces Coquín se define como hombre de burlas, en unos versos que hemos citado (vv. 755-761), y a los que precede un desafío implícito, pues el gracioso afirma ejercer un oficio que no necesita el rey: «teniendo un oficio yo / que vos no habéis menester» (vv. 739-740). La frase está diseñada para excitar la curiosidad del monarca, que inquiere de qué oficio se trata, ante lo que Coquín se define como gracioso. Esto provoca de nuevo una respuesta en don Pedro, que le propone a Coquín el famoso «concierto»:

REY Y pues sé quién sois, hagamos los dos un concierto.

Vitse, 2002, pp. 164, 170 y 173, por don Pedro. Relacionadas con estas lecturas sobre la crueldad del monarca suelen estar los comentarios sobre el concierto entre el rey y Coquín. Muy inverosímil resulta la propuesta de Carol Bingham Kirby, 1981, p. 131 y 2000 , p. 277, que ve en el comentario sobre los dientes del gracioso una burla regia sobre la supuesta impotencia de Coquín. Una interpretación diferente, pero también poco viable, es la de Maryrica Ortiz Lottman, 2003, p. 87. En esta línea se encuentra Cruz, 2001, que ve en las palabras del rey una amenaza de castración. De «figurative castration» habla también Fox, 2001, p. 210.

${ }^{24}$ Watson, 1963, 340. Más matizada es la visión de García Gómez, 1983, pp. 10301031, para quien el hecho de que el rey no se ría no es en sí ni loable ni reprensible. Sobre la recepción de la figura de don Pedro conviene consultar el estudio de Arellano, 2006.

${ }^{25}$ Cruickshank, 2010, p. 18. 
\begin{tabular}{ll} 
Coquín & \multicolumn{1}{c}{ ¿Y es? } \\
Rey & ¿Hacer reír profesáis? \\
Coquín & Es verdad. \\
Rey & \multicolumn{1}{c}{ Pues cada vez } \\
& $\begin{array}{l}\text { que me hiciéredes reír, } \\
\text { cien escudos os daré; } \\
\text { y si no me hubiereis hecho } \\
\text { reír en término de un mes, } \\
\end{array}$ \\
& os han de sacar los dientes.
\end{tabular}

(vv. 775-783)

Se trata de un desafio cómico, porque ese es el efecto que tenía en la convención de la comedia nueva la violencia dirigida contra los graciosos ${ }^{26}$. Además, el desafio es un reto del monarca al ingenio del gracioso, cuya capacidad de hacer reír usando sus mejores chistes tendrá que superar la del rey para reprimir la hilaridad: estamos ante un juego entre don Pedro y un hombre de placer ${ }^{27}$. Por tanto, el desafio de la dentadura es, más que un indicio de la crueldad o enfermiza seriedad del monarca, una muestra de su humor.

Dos detalles confirman esta interpretación jocosa, uno ya notado por la crítica y otro en el que los estudiosos no han reparado. El primero es el hecho de que el juego tome la forma no de una imposición tiránica, sino de un contrato que Coquín tiene que aceptar libremente ${ }^{28}$, como corresponde a un duelo de ingenio. Las palabras de Coquín al marcharse reflejan muy bien ese contexto de desafio lúdico, pues contienen tanto un reto como indicios de que el «concierto» ha picado su orgullo:

¡Voto a diez,

que os habéis de reír! Adiós,

${ }^{26}$ Armendáriz, 2007, p. 383. En las comedias cómicas el público reconocía estas situaciones como jocosas. Opera en ellas una anestesia afectiva, un tipo de distanciamiento que impedía que las escenas se interpretaran trágicamente (Vitse, 1988, p. 37).

27 Solo Kirby, 2000, p. 276, ha señalado el elemento de juego cortesano del concierto, aunque para él retrata la doble faceta — cruel o humana- del monarca.

${ }^{28}$ García Gómez, 1983, p. 1028, enfatiza este aspecto. Paterson, 1985, p. 198, ha notado cómo el «concierto» entre el rey y Coquín adopta el vocabulario de un contrato civil. 
y veámonos después.

(vv. 806-808)

Además, y en segundo lugar, don Pedro hace explícita la naturaleza lúdica del desafio en la tercera jornada, cuando Coquín le relata cómo don Gutierre se dispone a asesinar a doña Mencía. El rey quiere recompensar el servicio del criado y le pregunta con qué podrá pagarlo, ante lo que Coquín saca a relucir el concierto:

Con darme apriesa

libre sin más accidentes

de la acción contra mis dientes.

(vv. 2766-2768)

La respuesta del monarca es breve pero sumamente reveladora:

No es ahora tiempo de risa.

Don Pedro define el desafio con el gracioso como algo jocoso que contrasta con la grave situación presente, en la que ya no caben los juegos de las dos primeras jornadas. El concierto entre el monarca y su autodenominado hombre de placer es, pues, claramente "de risa» y en ningún caso indicio de la crueldad de don Pedro.

En este contexto lúdico de la primera y segunda jornada se integra el chiste de la bigotera, que Coquín define como «un cuento» "que remata en epigrama» (vv. 1460-1461) y que supone el primer y mayor asalto del gracioso a la hilaridad del monarca. El público está, pues, preparado para un chiste notable. Coquín cuenta, tras unos preliminares en que encarece la gracia de su broma, lo siguiente:

Yo vi ayer

de la cama levantarse

un capón con bigotera.

¿No te ríes de pensarle

curándose sobre sano

con tan vagamundo parche?

A esto un epigrama hice

(No te pido, Pedro el grande,

casas ni viñas; que solo 


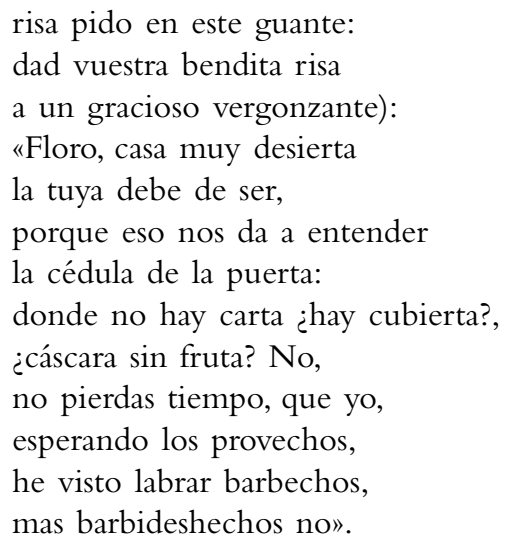

(vv. 1463-1484)

La crítica ha buscado interpretaciones a veces poco verosímiles para esta broma, como las ya citadas lecturas que ven en el capón una alusión a la impotencia de don Gutierre ${ }^{29}$, posibilidad que no sustenta el texto de la obra. Más aceptable parece la idea de que el capón con bigotera resume - jocosamente, añadiríamos - la preocupación de don Gutierre: si el capón se cura "sobre sano» poniéndose un parche donde no hay herida, don Gutierre, usando la misma metáfora médi$\mathrm{ca}$, sana su honor sin que tampoco fuera necesario hacerlo, pues doña Mencía no le era infiel ${ }^{30}$.

Sin embargo, el análisis más completo y convincente del pasaje nos parece el de Arellano, que examina la retórica del chiste encuadrando sus referencias eróticas en la tradición de bromas sobre capones (hombres afeminados y, en este caso, barbilampiños) y concluyendo que Coquín se burla de la incapacidad sexual del capón ${ }^{31}$. Pese a situar la broma en esa tradición jocosa, Arellano concluye subrayando la seriedad del rey don Pedro ante el epigrama (v. 1485). Para el estudioso navarro, la reacción se debe a que el chiste de Coquín es indecoroso e inapropiado para su destinatario (el rey), lo que motiva que sea recibido con semejante frialdad. Esta actitud, según Arellano, subra-

29 Cull, 1982, pp. 129-130; Cruz, 2001, pp. 229-230.

${ }^{30}$ Armendáriz, 2007, pp. 203-204; Bryans, 1982, p. 597; Cruickshank, 2010, pp. 20 y 147; Pérez Magallón, 2012, p. 287.

${ }^{31}$ Arellano, 1992, p. 755. 
yaría el ambiente trágico de El médico de su honra, que no tendría espacio para la risa ${ }^{32}$. Aunque el chiste está bien construido desde el punto de vista conceptual ${ }^{33}$, naufraga según Arellano por falta de decoro. Su fracaso representaría el triunfo de la tragedia sobre las burlas en una obra de impresión melancólica ${ }^{34}$. Esta opinión resulta paralela a la de la mayoría de los hispanistas, para quienes o Coquín es un gracioso incompetente ${ }^{35}$ o incapaz de aportar comicidad, ya sea por la crueldad y frialdad del rey y don Gutierre, ya por otros motivos. Fuera como fuere, la crítica concuerda en que los chistes de Coquín no traen comicidad al ambiente opresivo de El médico de su honra.

Esta opinión se basa, sin embargo, en la actitud de dos de los personajes, don Gutierre y don Pedro, sin tener en cuenta el contexto de las escenas en cuestión. En el primer caso, el contraste entre los chascarrillos de Coquín y la preocupación de don Gutierre por recibir decorosamente a su huésped ${ }^{36}$ produce una situación cómica, sobre todo teniendo en cuenta que a estas alturas de la comedia todavía no experimentamos la atmósfera opresora posterior. En el segundo caso, y como apuntamos arriba, la reacción de don Pedro tiene que verse enmarcada en el contexto de un desafío jocoso, el concierto entre el monarca y el gracioso, que supone un tour de force entre los dos personajes: Coquín se esfuerza por hacer reír al monarca, y este se afana por contener la risa, situación evidentemente cómica. Es más, el hecho de que don Pedro entre en semejante pacto con el criado supone la presencia de una clave jocosa, de un juego cómico que el público debió de apreciar y que no hace seria, sino más cómica, la reacción del monarca: don Pedro derrota al gracioso ahogando la risa ante su chiste, y desconcertándole con el «iqué frialdad!» que le espeta. En todo caso, los argumentos que se basan en la reacción de otros per-

32 Arellano, 1992, p. 760.

33 Otro tanto reconoce Cruickshank, 2010, p. 55. Pese a ello Cruickshank, 2010, pp. 57-58, adopta la lectura más común al considerar que este gracioso se halla melancólicamente aislado y que don Pedro no aprecia sus bromas por su severo e inhumano carácter.

${ }^{34}$ Arellano, 1992, pp. 760-761. Se podría alegar, por otra parte, que precisamente son las rupturas del decoro una de las principales fuentes de la comicidad de los graciosos.

35 Jones, 1961, p. XX; Armendáriz, 2007, p. 203.

36 Calderón de la Barca, El médico de su honra, pp. 362-65, vv. 427-483. 
sonajes de la obra pueden resultar peligrosos. Si acudimos exclusivamente a ellos no tendrían gracia la mayoría de los graciosos áureos, cuyos chascarrillos rara vez son celebrados con la hilaridad de sus señores, que normalmente o bien los ignoran o bien los censuran en obras que no han sido precisamente calificadas de universos trágicos excluyentes de la risa. Además, los chistes de los graciosos suelen caracterizarse, como los de Coquín, por la anfibología y por el contenido indecoroso. Por tanto, y en vista de estas dificultades y riesgos, conviene que consideremos las reacciones de los personajes de la obra ante Coquín al lado de argumentos que se basen en la probable actitud del público y lectores de El médico de su honra. Podemos intuir esa actitud si nos fijamos en la tradición de algunas de estas bromas, como la del capón con bigotera.

La bigotera fue uno de los más curiosos y comentados adminículos de la moda barroca española, hasta el punto que un experto como William E. Wilson la anteponga en ridiculez a los cuellos escarola$\operatorname{dos}^{37}$. La bigotera era una necesidad provocada por la moda de llevar los mostachos erguidos de guías, lo que les daba una forma de arco turquesco muy apreciada, y que se percibe, por ejemplo, en retratos de Felipe III y, especialmente, Felipe IV.

37 Wilson, 1955, p. 29. Sobre el impacto de los cuellos en la literatura áurea ver Sánchez Jiménez, 2002. Sobre la bigotera como parte de la cultura material del Madrid del XVII véase Enrique García Santo-Tomás, 2004, p. 50. 


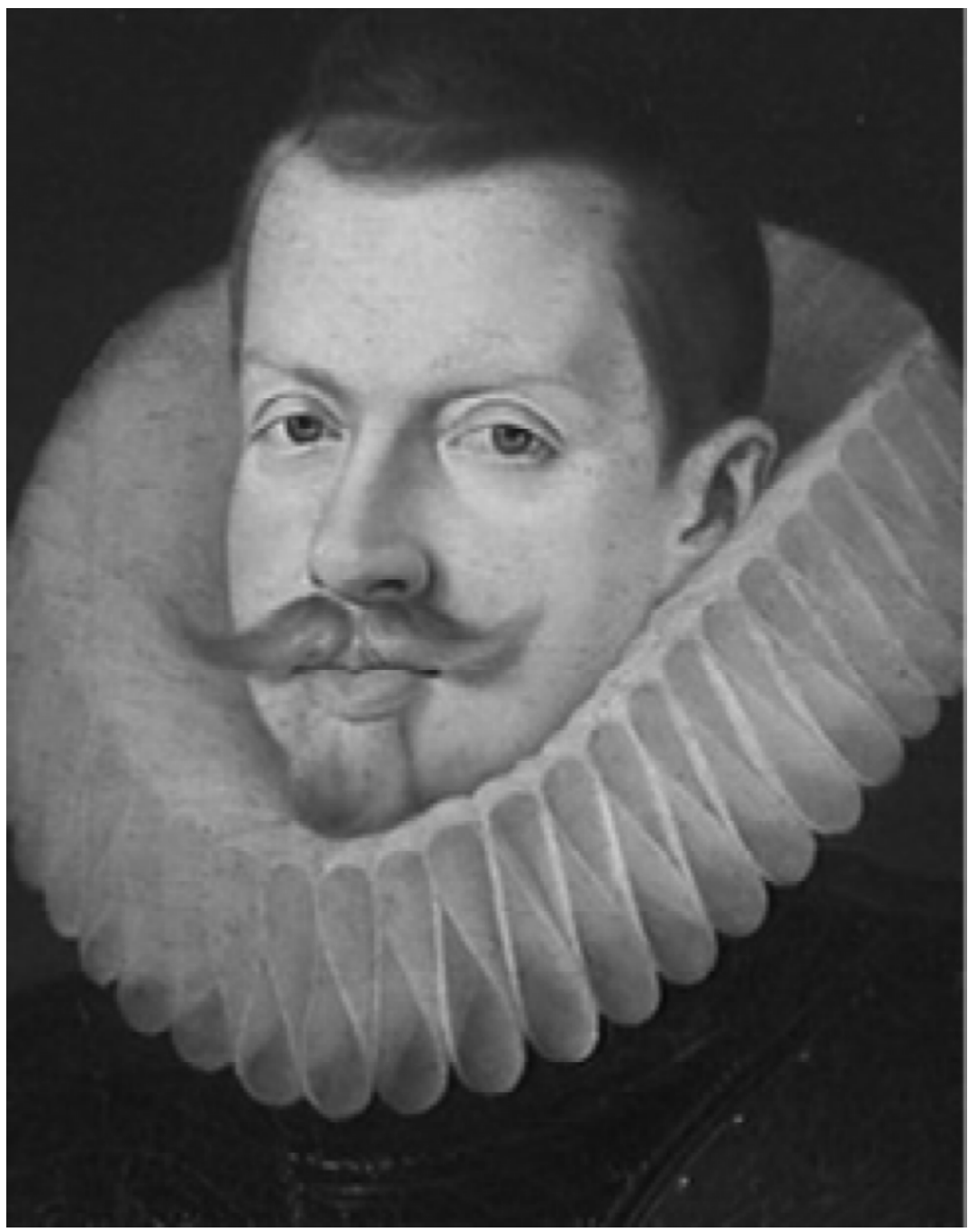

Andrés López, Felipe III,

Kunsthistorisches Museum, Viena, c. 1617. 


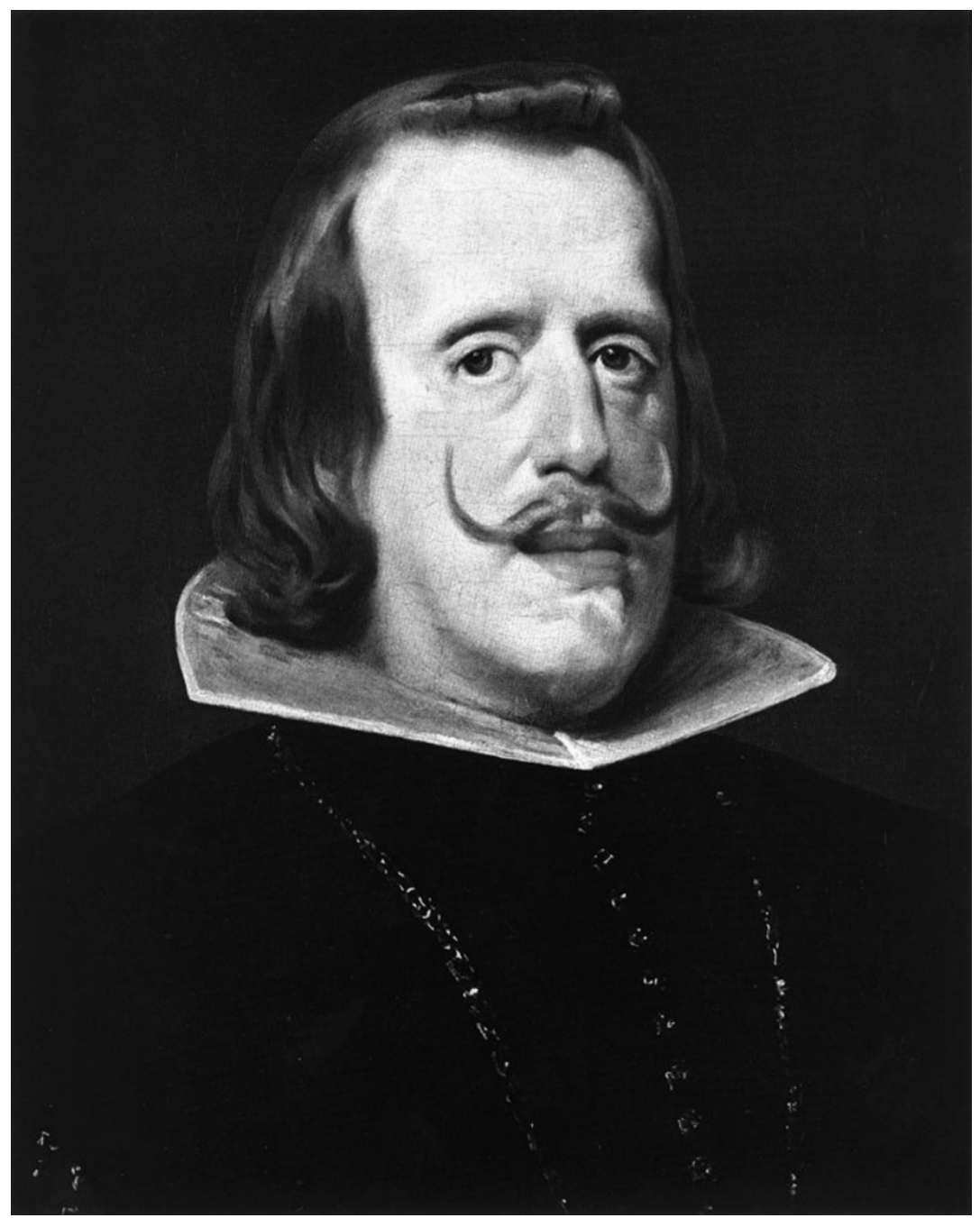

Diego Velázquez, Felipe IV, Kunsthistorisches Museum, Viena, 1652. 
Para que adquirieran esa forma, los bigotes se manipulaban con unas pinzas y tenacillas ad $h c^{38}$, y para que mantuvieran la pose desafiando la gravedad se untaban de goma aromática y se guardaban (durante la noche, o cuando se estaba en casa, que de los dos casos tenemos testimonios) en la bigotera, una funda especial hecha de cuero y tratada con sustancias aromáticas. El curioso artículo debió de inventarse y extenderse hacia 1611 o $1612^{39}$, y por tanto no aparece definido en el Tesoro de Sebastián de Covarrubias Horozco, pero sí en el Diccionario de Autoridades ${ }^{40}$. La definición viene autorizada por dos ejemplos áureos, una premática de 1680 y un pasaje de la "Casa de los locos de amor» (1648) de Francisco de Quevedo ${ }^{41}$, autor que resume la actitud de los escritores de la época hacia la bigotera, que es jocosa y satírica:

Otros querían enamorar por lo lindo, muy preciados de tufos y guedejas, manos blancas y pies chicos, con zapatos romos, grandes encubridores de juanetes y sobrehuesos, teniendo ellos más que un mal calado, siendo un Lucifer en la cara, y con esfuerzo en el talle, sin saber que siempre quieren ellas ser las lindas de casa. De estos, uno vi que, de puro haber tenido los bigotes en pena y enfrenados toda la noche con su bigotera, como si fuera braquillo o gozque, y siendo peor que macho, que este no duerme con freno, los traía a las estrellas ${ }^{42}$.

El protagonista es un «lindo», galán a la nueva usanza que Quevedo caracteriza por una preocupación excesiva y afeminada por su apariencia, manía que el escritor denuncia equiparando esta costumbre a las del bello sexo y denunciándola como un modo engañoso de blanquear y ocultar defectos. A continuación, Quevedo rebaja al lindo centrándose en la bigotera, que equipara jocosamente con una penitencia de bigotes y, sobre todo, con el freno de los animales. Además de en este pasaje, la bigotera aparece satirizada en varias obras del siglo XVII, y siempre en un contexto de burla satírica, muchas veces ligada con una nueva y censurable idea de la masculinidad. Los pasajes que

38 Castillo Solórzano, Aventuras del Bachiller Trapaza, p. 179.

${ }^{39}$ Wilson, 1955, pp. 29-30; Wilson, 1973, p. 44.

40 Aut, p. 608.

41 Aut, p. 608.

42 Quevedo y Villegas, "Casa de los locos de amor», p. 244. 
reúnen estas características son abundantes: una búsqueda del vocablo «bigotera» en el CORDE arroja 23 testimonios, 11 en prosa narrativa (44\%), 9 en verso lírico $(36 \%)$ y 5 en verso dramático $(20 \%)^{43}$. Además, podemos añadir otras obras: en primer lugar, algunas ya apuntadas por Wilson en su breve trabajo sobre la bigotera ${ }^{44}$, o por Jesús Terrón González en su Léxico de cosméticos y afeites en el Siglo de Oro ${ }^{45}$. Estos testimonios dibujan un claro panorama: en la literatura áurea la bigotera es blanco de sátiras y burlas, ya como símbolo del afeminamiento de los hombres al uso, ya como mecanismo para contrastar la realidad y las apariencias, y dar por tanto entrada al desengaño. Como ejemplo de la sátira de lindos en la comedia puede servir El lindo don Diego, y en concreto el pasaje en el que el gracioso Mosquito —nótese cómo en el teatro la mención de la bigotera parece exclusiva del gracioso - describe a don Diego, que, según él, «tiene / más que de Diego de lindo» ${ }^{46}$ :

Era el cabello, hecho trenzas,
clin de caballo morcillo,
aunque la comparación
de rocín a ruin ha ido.
Con su bigotera puesta
estaba el mozo jarifo,
como mulo de arriero
con jáquima de camino;
las manos en unos guantes
de perro, que por aviso
del uso de los que da,
los aforra de su oficio ${ }^{47}$.

Mosquito censura al lindo poniendo en duda su masculinidad, mediante esta lista de los cuidados a que se somete durante la noche, entre los que destacan los dedicados a sus guedejas —el pelo largo era

43 Real Academia Española: Banco de datos (CORDE) [en línea]. Corpus diacrónico del español, <http://www.rae.es> [27 de septiembre de 2012].

44 Wilson, 1955.

45 Terrón González, 1990, p. 75.

46 En el caso de don Diego, sí que existe una referencia directa en el chiste del gracioso a la impotencia del personaje, como ha demostrado García Ruiz, 1987.

47 Moreto, El lindo don Diego, pp. 47-48, vv. 315-316 y 349-360. 
atributo de lindos ${ }^{48}$ - , los guantes de piel de perro para conservar la delicadeza de las manos y, por supuesto, la ya inevitable bigotera, que Moreto menciona con la familiar comparación con un mulo enfrenado, que animaliza al Adonis. Estamos ante un pasaje burlesco en que el gracioso ridiculiza la bigotera, y que resulta representativo de los textos de nuestro corpus en que se relaciona el adminículo con los lindos. En cuanto al segundo caso - la bigotera como símbolo de las apariencias y engaños de la sociedad- es de nuevo Quevedo quien proporciona un buen ejemplo de su uso con su burla de don Diego de Noche en el Sueño de la Muerte. Don Diego, caballero chirle que lo hace todo por aparentar, aparece "penando en una bigotera de fuego", artilugio penitencial que remeda los varios adminículos que usaba en vida para su vano vestuario: "porque, siendo gentilhombre mendicante, caminaba con horma y bigotera a un lado y molde para el cuello y la bula en el otro» ${ }^{49}$. En suma, contra lindos o contra apariencias, el humor es la nota dominante en las menciones áureas de la bigotera, especialmente cuando el adminículo se relaciona con el tema del chiste de Coquín: el hombre poco varonil, muchas veces caracterizado directamente como «lindo" ${ }^{50}$.

Entre estas pullas contra las bigoteras destacan las de dos textos concretos, Todo es ventura y las Rimas de Tomé de Burguillos, menciones que por su cercanía léxica con el chiste de Coquín pudieron ser la fuente de Calderón. El primero se encuentra en la citada comedia de Juan Ruiz de Alarcón, que salió impresa en 1628:

Marqués ¿Qué es eso?

TRISTÁN

Un parche, y por Dios

que sé yo quien en su casa, para no ver lo que pasa, tiene puestos siempre dos; que sus poltrones resabios ponen, trocando despojos,

${ }^{48}$ Las guedejas suelen ser satirizadas en muchos de los textos que ridiculizan las bigoteras. Sobre la preocupación por estas nuevas formas de masculinidad en el siglo XVII conviene consultar el trabajo de Lehfeldt, 2008.

49 Quevedo y Villegas, Los sueños, p. 387.

50 Gómez Canseco, 2009, pp. 332-333. 
la bigotera en los ojos,

los antojos en los labios ${ }^{51}$.

Ruiz de Alarcón incluye el adminículo en un contexto jocoso, concretamente un chiste en labios de un gracioso, y además utiliza como Calderón la palabra "parche». Sin embargo, el contenido de la broma es muy diferente: no satiriza a los hombres afeminados, como Coquín, sino más bien a los maridos consentidos, y la mención del parche, aunque se utiliza también para subrayar lo ridículo de la bigotera, no tiene relación con la metáfora médica de Calderón. Mucho más parecida es la aparición de la palabra en las Rimas de Tomé de Burguillos (1634) de Lope de Vega, texto más cercano cronológicamente a El médico de su honra. En este libro de burlas la bigotera se encuentra en tres sonetos, desempeñando un papel diverso.

En el número 44 ( A un zapato muy grande y desaseado de una dama») solo aparece como término hiperbólico de comparación, para enfatizar la pequeñez de los pies de la dama (cuyos zapatos son tan minúsculos y delicados que pueden servir de bigotera) en contraste con el «zapato cruel» que se ridiculiza en el poema ${ }^{52}$. Mucho más central es el papel de la bigotera en el soneto 33 («Envió una dama una bigotera de ámbar a un galán, que no la había menester»), que ridiculiza a un "galán Narciso» lampiño a quien su dama envía una bigotera, pero que por su carencia de bigotes — que sugiere una virilidad disminuida, como la del capón calderoniano- él no va a utilizar ${ }^{53}$. Igualmente importante es la bigotera en el siguiente soneto (número 34 en la edición de Carreño, "Aún no dejó la pluma y prosigue»), que sigue ridiculizando al galán lampiño ${ }^{54}$, inserto en el ya familiar campo semántico del «lindo»:

51 Ruiz de Alarcón, Todo es ventura, p. 126.

52 Vega Carpio, Rimas de Tomé de Burguillos, p. 200, vv. 5-8.

${ }^{53}$ Vega Carpio, Rimas de Tomé de Burguillos, p. 185, vv. 12-14.

54 Según Juan Manuel Rozas, 1990, p. 156, el galán cuya hombría se ridiculiza es José de Pellicer. Este enemigo de Lope era lampiño, como demuestra Rozas, 2005, p. 168, pero el texto no justifica que fuera precisamente Pellicer, y no otro lampiño, o un lampiño en general, el blanco de la sátira. De hecho, la abundancia de chistes sobre la bigotera y los lindos parece indicar que estamos ante una sátira de un tipo, más que de un personaje histórico concreto. Igualmente aventurado parece el comentario de Margarita Cuiñas Gómez, 2008, p. 179, que sugiere que la «Elena» a quien se dirige el primer soneto podría ser Elena Osorio. 
Al galán de la linda bigotera, que dicen que sin ella os enamora ${ }^{55}$.

Además, y lo que es más interesante para nuestro propósito, el concepto final del soneto utiliza un vocabulario del que luego se hará eco El médico de su honra:

Para el frío será cosa escogida, que bigotera en un lampiño eterno es poner parche donde no hay herida ${ }^{56}$.

Estamos ya ante el campo semántico de la medicina que domina la tragedia de Calderón ${ }^{57}$, y que el dramaturgo tomó de la versión anterior de la obra, El médico de su honra atribuida al propio Lope. Si en el texto modelo la metáfora aparece esporádicamente, Calderón la adopta hasta convertirla en parte central de su tragedia, por lo que resulta sugerente que también aparezca en el chiste de Coquín, e incluso en la broma del Burguillos.

Por lo menos podemos afirmar que Calderón conocía ya a este personaje lopesco y que le era familiar su jocosa animadversión por las bigoteras, pues en la Justa poética a la beatificación de san Isidro, organizada por Lope en 1620 y en la que participó Calderón, Burguillos se opone a los lindos aludiendo a la bigotera, o más bien a su función y efecto, que era dejar los bigotes con guías muy levantadas:

Pero si yo jamás traje guedejas,

ni el rostro en nube de celestes bandas,

ni casé los bigotes con las cejas,

ni fui escudero de Guacolda en andas, ¿por qué de tu Castalia me despejas? ${ }^{28}$

De hecho, los chistes sobre bigoteras parecían ser una especialidad lopesca, pues el madrileño los emplea con llamativa frecuencia -15

${ }^{55}$ Vega Carpio, Rimas de Tomé de Burguillos, p. 186, vv. 1-2.

${ }^{56}$ Vega Carpio, Rimas de Tomé de Burguillos, p. 186, vv. 12-14.

57 Cruickshank, 2010, pp. 16-18.

${ }^{58}$ Lope de Vega, Justa poética a la beatificación de san Isidro, p. 486, vv. 33-37. 
textos de los 47 que componen nuestro corpus bigoteril son de Lope- Además, resultan particularmente apreciados por Burguillos, que en la Justa poética de san Isidro en su canonización, de 1622, vuelve a equiparar los «barbados galanes» que "se encajan las bigoteras» con otras figuras igualmente protagonistas de las sátiras contra las modas del momento, como son las damas que se ponen demasiados afeites o los calvos que usan pelucas ${ }^{59}$. El hecho de que Calderón participara en ambas fiestas, el hecho de que conociera bien a Burguillos y el hecho de que las Rimas de este heterónimo aparecieran en 1634 sugiere que el autor de La vida es sueño pudo inspirarse en el soneto de Burguillos para construir su chiste de Coquín, especialmente si tenemos en cuenta que Calderón aprovecha el concepto del epigrama lopesco en la primera parte del cuento de su gracioso: poner bigotera en el capón es curarse sobre sano, "poner parche donde no hay herida».

Con este contexto burlesco de los chistes sobre bigoteras, más la fuente jocosa del texto de Calderón, y más la interpretación interna antes aducida, concluimos que el cuento de Coquín sería recibido en la época con la hilaridad que se merece, provocando sonora risa a costa de los lindos y las bigoteras. El público y los lectores de El médico de su honra entenderían que don Pedro de Castilla, que había hecho el jocoso concierto con Coquín para poder escuchar bromas como esta, encontraría muy gracioso el cuento del capón con bigotera. Los receptores también debieron de entender que, no obstante esa gracia, y debido a la divertida lucha de ingenio con el criado, el monarca logró contener la risa para derrotar al gracioso en su terreno, en una escena de gran comicidad. Por tanto, en lo que a Coquín y sus bromas se refiere, el ambiente opresivo de El médico de su honra no se extiende a la totalidad de la primera y segunda jornadas. En ellas el gracioso deleita al público con chistes y escenas jocosas como la del concierto con don Pedro, en la que llega a participar el propio rey, que es, no olvidemos, quien propone el tour de force. Este desafio, y el chiste del capón con bigotera dentro de él, traen la risa a la comedia, al menos hasta llegar al punto de inflexión de la tercera jornada. En ella, como comprobamos anteriormente, el papel del gracioso cambia radicalmente y Coquín pasa a funcionar más como funesto nuncio

${ }^{59}$ Lope de Vega, Justa poética a san Isidro en su canonización, p. 557, vv. 9-13. 
que como hombre de placer. En este sentido, su autoproclamada transición de burlas a veras es totalmente cierta, así como su paso de gracioso convencional - fiel y cómico- a atípico —infiel y serio- ${ }^{60}$.

En ese contexto, el chiste del capón con bigotera podría tener la función premonitoria que le atribuyen algunos: la inútil preocupación de Gutierre por el honor se vería reflejada por la que muestra capón por el estado de su inexistente bigote, también expresada con vocabulario médico. Sin embargo, el efecto principal del chiste sería el primario de los graciosos áureos, el contraste: la jocosidad de Coquín se contrapone con la seriedad de don Gutierre y doña Mencía, y con la reacción posterior del propio Coquín, que en la tercera jornada abandonará las bromas contagiado, esta vez sí, por el tenebroso ambiente. El chiste muestra que, como dice el rey don Pedro, la tercera jornada no es «tiempo de risa» ${ }^{61}$, pero que las anteriores sí lo fueron, contraste que motiva que el monarca tenga que especificarlo. En este sentido, El médico de su honra respondería al patrón que notó Arellano en las tragedias o comedias serias, en las que graciosos como Coquín «están ahí para demostrar la fuerza de la tragedia que los contamina sin remedio" ${ }^{62}$, en este caso en la última jornada. Es decir, el tratamiento jocoso de la bigotera realza por contraste las consecuencias trágicas de los actos del sangrador: las luces del gracioso en las dos primeras jornadas resaltan las sombras que se ciernen sobre la obra y la inundan con el asesinato de doña Mencía y la agonía de don Gutierre.

${ }^{60}$ Vitse, 1983, p. 1067.

61 Calderón de la Barca, El médico de su honra, p. 477, v. 2769.

62 Arellano, 2011, p. 243. 


\section{BibliografíA}

Arellano, I., "Un chiste de Coquín: el epigrama a Floro en El médico de su honra, de Calderón", en Actas del X Congreso de la Asociación Internacional de Hispanistas (Barcelona, 21-26 de agosto de 1989), ed. A. Vilanova, Barcelona, PPU, 1992, pp. 755-761.

- Historia del teatro español del siglo XVII, Madrid, Cátedra, 1995.

— «"Decid al rey cuánto yerra". Algunos modelos de mal rey en Calderón», en El teatro clásico español a través de sus monarcas, ed. L. García Lorenzo, Madrid, Fundamentos, 2006, pp. 221-237.

- El arte de hacer comedias. Estudios sobre teatro del Siglo de Oro, Madrid, Biblioteca Nueva, 2011.

Armendáriz Aramendía, A., «Don Gutierre: ¿monstruo o héroe?», en Calderón 2000. Homenaje a Kurt Reichenberger en su 80 cumpleaños, ed. I. Arellano, vol. II, Kassel, Reichenberger, 2002, pp. 35-48.

- Edición crítica de El médico de su honra de Calderón de la Barca, Madrid / Frankfurt, Iberoamericana / Vervuert, 2007.

Azcue Castillón, V., "La política de la información en El médico de su honra», en Calderón 2000. Homenaje a Kurt Reichenberger en su 80 cumpleaños, ed. I. Arellano, vol. II, Kassel, Reichenberger, 2002, pp. 63-72.

Blue, W. R., «La cédula de la puerta: el cuento de Coquín», Romance Notes, 20, 1979-80, pp. 242-247.

— «El médico de su honra and the Politics of Reading», Hispania, 82, 1999, pp. 408-416.

Bryans, J., "Coquín's Conversion: Honour, Virtue, and Humour in El Médico de su Honra», The Modern Language Review, 77, 1982, pp. 597-605.

Calderón de la Barca, P., El médico de su honra, ed. A. Armendáriz Aramendía, Madrid / Frankfurt, Iberoamericana / Vervuert, 2007.

Casa, F. P., "Honor and the Wife-Killers of Calderón», Bulletin of the Comediantes, 29, 1977, pp. 6-23.

- «Las muertes entrelazadas de El médico de su honra» en Palabra crítica: estudios en homenaje a José Amezcua, ed. S. González y L. von der Walde Moheno, México, UNAM, 1997, pp. 136-145.

Couderc, C., "El médico de su honra de Calderón entre la ejemplaridad moral y la ejemplaridad estética», Criticón, 110, 2010, pp. 67-77.

Covarrubias Horozco, S. de, Tesoro de la lengua castellana o española [1611], ed. I. Arellano y R. Zafra, Madrid / Frankfurt, Iberoamericana / Vervuert, 2006.

Cruickshank, D. W. (ed.), P. Calderón de la Barca, El médico de su honra, de Madrid, Castalia, 2010.

Cruz, A. J., «Eunuchs and Empty Houses: Coquín's Tragic Joke in El médico de su honra», Bulletin of the Comediantes, 53, 2001, pp. 217-235. 
Cuiñas Gómez, M., ed., Rimas de Tomé de Burguillos, de L. de Vega Carpio, Madrid, Cátedra, 2008.

Cull, J. T., «La función de los celos en El médico de su honra», Segismundo, 16, 1982, pp. 115-136.

Diccionario de Autoridades, 3 vols., Madrid, Francisco Hierro, 1726-1737.

Díez Borque, J. M. ${ }^{a}$, Sociedad y teatro en la España de Lope de Vega, Barcelona, Bosch, 1978.

Escudero, J. M., «El gracioso trágico calderoniano: un caso de multiplicidad», Anuario Calderoniano, 3, 2010, pp. 115-135.

Fox, D., «El médico de su honra: Political Considerations», Hispania, 65, 1982, pp. 28-38.

— "“Notable sujeto!”: Terms of Dismemberment in El médico de su honra», Bulletin of the Comediantes, 53, 2001, pp. 197-216.

García Gómez, A. M., "El médico de su honra: perfil y función de Coquín", en Calderón. Actas del Congreso Internacional sobre Calderón y el teatro espanol del Siglo de Oro (Madrid, 8-13 de junio de 1981), ed. L. García Lorenzo, vol. II, Madrid, CSIC, 1983, pp. 1025-1037.

García Ruiz, V., «Una nota explicativa a El lindo don Diego, de Moreto: Mosquito revela la impotencia sexual de don Diego", en La edición de textos: actas del I Congreso Internacional de Hispanistas del Siglo de Oro, ed. P. Jauralde Pou, D. Noguera y A. Rey, London, Tamesis, 1987, pp. 209-217.

García Santo-Tomás, E., «Introducción», en Las bizarrías de Belisa, de L. de Vega Carpio, ed. E. García Santo-Tomás, Madrid, Cátedra, 2004, pp. 977.

Gaylord Randel, M., "Amor y honor a través del espejo», en Calderón. Actas del Congreso Internacional sobre Calderón y el teatro español del Siglo de Oro (Madrid, 8-13 de junio de 1981), ed. L. García Lorenzo, vol. II, Madrid, CSIC, 1983, pp. 869-879.

Gómez Canseco, L., «Entre tanta tontería...: tontos de veras en Lope», en En buena compañía. Estudios en honor de Luciano García Lorenzo, ed. J. Álvarez Barrientos et alii, Madrid, CSIC, 2009, pp. 329-340.

Hesse, E. W., "Honor and Behavioral Patterns in El médico de su honra», Romanische Forschungen, 88, 1976, pp. 1-15.

Jones, C. A., ed., El médico de su honra, de P. Calderón de la Barca, Oxford, Oxford University Press, 1961.

Kirby, C. B., «Theater and History in Calderón's El médico de su honra», Journal of Hispanic Philology, 5, 1981, pp. 123-135.

- «El gracioso en dos dramas calderonianos de honor conyugal: el arte de la imitación", en Calderón: protagonista eminente del barroco europeo, ed. K. y T. Reichenberger, Kassel, Reichenberger, 2000, pp. 271-279.

Lehfeldt, E.A., «Ideal Men: Masculinity and Decline in Seventeenth-Century Spain», Renaissance Quarterly, 61, 2008, pp. 463-494. 
Ortiz Lottman, M., "The Toothsome Mouth in El médico de su honra», Bulletin of the Comediantes, 55, 2003, pp. 87-108.

PArker, A.A., "Aproximación al drama español del Siglo de Oro», en Calderón y la crítica, ed. M. Durán y R. González Echevarría, vol. I, Madrid, Gredos, 1976, pp. 329-357.

- «La tragedia de honor: El médico de su honra», en La imaginación y el arte de Calderón. Ensayos sobre las comedias. Madrid: Cátedra, 1991, pp. 265-291.

Paterson, A. K. G., "El proceso penal en El médico de su honra», en Hacia Calderón. Séptimo coloquio anglo-germano, ed. Hans Flasche, Stuttgart, Steiner, 1985, pp. 194-203.

Pedraza Jiménez, F. B., Calderón. Vida y teatro, Madrid, Alianza, 2000.

Pérez Magallón, J. (ed.), P. Calderón de la Barca, El médico de su honra, Madrid, Cátedra, 2012.

Quevedo y Villegas, F. de, "Casa de los locos de amor», en Enseñanza entretenida y donairosa moralidad comprendida en el archivo ingenioso de las obras escritas en prosa, Madrid, Diego Díaz de la Carrera, 1648, pp. 237-251.

- Poesía original completa, ed. J. M. Blecua, Barcelona, Planeta, 1990.

- Prosa festiva completa, ed. C. C. García-Valdés, Madrid, Cátedra, 1993.

- Los sueños, ed. I. Arellano, Madrid, Cátedra, 1991.

Real Academia Española, Banco de datos (CORDE) [en línea]. Corpus diacrónico del español, <http://www.rae.es> [27 de septiembre de 2012].

Rogers, D., "“Tienen los celos pasos de ladrones": Silence in Calderón's El médico de su honra», Hispanic Review, 33, 1965, 273-289.

- "El médico de su honra de Calderón y El conde de Sex de Coello», en Hacia Calderón: séptimo Coloquio Anglogermano, Cambridge, 1984, ed. H. Flasche, Wiesbaden, F. Steiner, 1985, pp. 175-182.

Rozas, J. M., Estudios sobre Lope de Vega, Madrid, Cátedra, 1990.

- y J. Cañas Murillo, ed., Rimas de Tomé de Burguillos, de L. de Vega Carpio, Madrid, Castalia, 2005.

Ruano de la Haza, J. M., ed., El alcalde de Zalamea, de P. Calderón de la Barca, Madrid, Espasa-Calpe, 1988.

Ruiz de Alarcón, J., Todo es ventura, Comedias de don Juan Ruiz de Alarcón y Mendoza, ed. J. E. Hartzenbusch, Madrid, Rivadeneyra, 1852, pp. 119-137.

SÁNCHEZ JimÉNEZ, A., "Cuellos, valonas y golillas: leyes suntuarias y crítica política en No hay mal que por bien no venga, de Juan Ruiz de Alarcón», Bulletin of the Comediantes, 54.1, 2002, pp. 91-113.

Shergold, N. D., y J. E. VArey, «Some Early Calderón Dates», Bulletin of Hispanic Studies, 38, 1961, pp. 274-286.

Sloman, A. E., The Dramatic Craftmanship of Calderón. His Use of Earlier Plays, Oxford, Dolphin, 1958.

Stroud, M., Fatal Union: A Pluralistic Approach to the Spanish Wife-Murder Comedias, Lewisburg, Bucknell University Press, 1990. 
Sullivan, H. W., "The Problematic of Tragedy in Calderón's El médico de su honra», Revista Canadiense de Estudios Hispánicos, 5, 1981, pp. 355-373.

Terrón González, J., Léxico de cosméticos y afeites en el Siglo de Oro, Cáceres, Universidad de Extremadura, 1990.

Vega Carpio, L. de, Justa poética que hace la insigne Villa de Madrid a la beatificación del bienaventurado san Isidro, su patrón, Lope de Vega, Poesía, VI, ed. A. Carreño, Madrid, Biblioteca Castro, pp. 443-488.

- Justa poética en que la insigne Villa de Madrid pretende celebrar las virtudes y milagros de su humildísimo e inocentísimo hijo y patrón san Isidro, en su canonización, por nuestro muy santo padre Gregorio XV, Lope de Vega, Poesía, VI, ed. A. Carreño, Madrid, Biblioteca Castro, pp. 525-589.

- Relación de las fiestas que la insigne Villa de Madrid hizo en la canonización de su bienaventurado hijo y patrón san Isidro, Madrid, 1622.

- Rimas de Tomé de Burguillos [1634], ed. A. Carreño, Salamanca, Almar, 2004.

Vitse, M. «De Galindo a Coquín», Calderón. Actas del Congreso Internacional sobre Calderón y el teatro español del Siglo de Oro (Madrid, 8-13 de junio de 1981), ed. L. García Lorenzo, vol. II, Madrid, CSIC, 1983, pp. 1065-1073.

- Éléments pour une théorie du théâtre espagnol du XVIIe siècle, Toulouse, Université de Toulouse-Le Mirail, 1988.

— «Calderón trágico», Anthropos, Extra 1, 1997, pp. 61-64.

- «Del canon calderoniano: el singular caso de El médico de su honra o prolegómenos para la historia de una catonización", en El teatro del Siglo de Oro ante los espacios de la crítica. Encuentros y revisiones, ed. E. García SantoTomás, Madrid / Frankfurt, Iberoamericana / Vervuert, 2002, pp. 307334.

— «Gutierre Alfonso de Solís», Calderón 2000. Homenaje a Kurt Reichenberger en su 80 cumpleaños, ed. I. Arellano, vol. I, Kassel, Reichenberger, 2002, pp. 163-186.

Watson, A. I., «Peter the Cruel or Peter the Just? A Reappraisal of the Role Played by King Peter in Calderón's El médico de su honra», Romanistisches Jahrbuch, 14, 1963, pp. 332-346.

Wilson, W. E., «Bigoteras and the Date of Lope's El cuerdo en su casa», Bulletin of the Comediantes, 7, 1955, pp. 29-31.

- Guillén de Castro, New York, Twayne, 1973.

Wiltrout, A. E., «Decoro y risa: dos motivos dramáticos en El médico de su honra de Pedro Calderón de la Barca», en Calderón, ed. L. García Lorenzo, Madrid, CSIC, 1983, pp. 661-669. 